\title{
A Reforma Administrativa e a Sistemática de Pessoal
}

JosÉ MEdeIros

A fico, do análise desapaixonada, sob o prisma exclusivamente cientíobservador de sã conscimparcial ao mais completo desencanto. Com efeito, público se apresenta se pode deixar de reconhecer que o serviço estrutura e em seuta defeituoso, arcaico e inoperante em sua de alcancar as feu funcionamento. É preciso dinamizá-lo, a fim Fropõe.

guardião das instituicũo há muito, de representar um simples maior intensidade, nas ões privadas, para interferir, com menor ou - Estado policial nas mais variadas atividades humanas. Assim, ação do Século XX. Século XVIII se transformou no Estadodo «laisser faire, laisser vai longe, pois, a época sócio-econômića uma interferência laisser passer». Exige-se, hodiernamente, senão mas pelo merencia direta e drástica, à moda socialista-soviética, essenciais à vida acentuados contrôle e coordenação das atividades

a dida nacional

O exigido reaparelhamento da Administração Pública, para atender a tão gigantescas atribuições, sòmente poderá ser realizado através de autêntica revolução administrativa, considerada a expressão em seu sentido orgânico e em sua concepção funcional.

Atualmente, os Ministérios constituem agrupamentos desámônicos de órgãos, sem a imprescindivel coordenação entre êles. Isso porque êsses órgãos foram sendo instituídos, através dos tempos, sem observância a uma planificação em que se considerasse o conjunto administrativo como uma orquestra sinfônica devidamente ensaiada para reproduzir as obras dos mestres da música. E quase sempre tal criação não era precedida de verifiração da existência de entidades que porventura já viessem realizando as atividades cometidas aos novos órgãos, o que fas. Não era raro, duplicidade ou mesmo triplicidade de taredessas entida incomum mesmo o prévio conhecimento da existência finalidades, sem mas, apesar disso, criavam-se outras com idênticas 
que subsistiam graças à índole tão brasileira de não destruir os velhos tabus.

A desorganização estrutural, por conseguinte, vem afetando o próprio funcionamento do complexo administrativo, que ainda se ressente de métodos modernos e científicos de trabalho e sobrepairando a todos os demais elementos - de pessoal com as qualificações indispensáveis.

$\mathrm{Na}$ realidade, não adianta idealizar ou implantar a mais moderna máquina administrativa, com a utilização dos mais aperfeiçoados métodos de trabalho se, para movimentá-la, não se contar com elemento humano capacitado e treinado para realizar as atividades em tôdas as suas graduações. Não há como discutir - pois já se erigiu em axioma - que por trás de todo e qualquer empreendimento há sempre o homem, de cujos comportamento e atuação dependem o êxito ou o malôgro da emprêsa. É oportuno ressaltar que êsse estado de coisas não escapou à argúcia do Presidente Costa e Silva, que colocou o humanismo social como centro e base de sua filosofia governamental.

A revolução administrativa, em sua concepção orgânica, estrutural, já se iniciou com o advento do Decreto-lei n? 200 , de 25 de fevereiro de 1967, que dispõe sôbre a organização da Administração Federal e estabelece diretrizes para a Reforma Administrativa, mas a sua implantação ainda está no nascedouro, na expectativa dos atos complementares que venham corporificar os seus princípios.

Dentro do panorama que se procurou esboçar, em rápidas pinceladas, a situação atual da Administração de Pessoal no serviço público brasileiro é desenganadamente desalentadora. A sua visualização pode ser assim sintetizada: um exército de cêrca de 700.000 servidores, em sua maioria despreparados para a missão que lhes incumbe realizar, sujeitos a uma legislação desordenada e caótica e, além disso, terrivelmente mal remunerado.

$O$ velho ideal de codificação uniforme, em que se determinassem os direitos e vantagens, bem como os deveres e responsabilidades, desmoronou-se aos primeiros contatos com a distorcida realidade brasileira. É fato incontestável a existência do Estatuto dos Funcionários Públicos Civis da União (Lei n ${ }^{\circ} 1.711$, de 28 de outubro de 1952). Mas, com o perpassar dos tempos, essa meritória tentativa de codificação foi-se desfazendo sob o impulso da multiplicidade de leis de caráter discriminatório, que asseguraram situações de privilégio para determinados agrupamentos de servidores. Assim, e ainda em seu alvorecer, a sistemática estatutária foi desarticulada, como delicado brinquedo em inexperientes mão infantis, com o advento da Lei $\mathrm{n}^{\circ} 1.741$, de 22 de novembro de 1952. Assegurou êsse diploma legal aos seus ocupantes de cargo em comissão, após dez anos ininterruptos 
de exercício, o direito de continuarem percebendo os vencimentos do comissionamento. Trata-se de autêntica, embora disfarçada, modalidade de estabilidade financeira, que se contrapõe, frontalmente, ao princípio geral de que os cargos em comissão são providos pelo critério exclusivo da confiança, ficando os respectivos e eventuais ocupantes sujeitos à demissibilidade ad nutum, e sem nenhum direito à permanência no cargo ou a continuarem percebendo as correspondentes vantagens pecuniárias quando à Administração convir afastá-los.

Por outro lado, e de modo geral, os funcionários não estão técnica, intelectual e psicològicamente preparados para o desempenho das atribuições que devem executar. A carência de conhecimentos básicos da matéria a que cabem manipular cotidianamente, irmanada ao desconhecimento ou à imprecisão da importância de sua missão e a do órgão em que trabalha, incapacitam tais funcionários para o cabal exercício de seus cargos. As causas são múltiplas e de suas análise e solução dependem a

implantação de um sistema administrativo racional e eficiente.
A incapacidade de realização de suas tarefas, por parte do funcionalismo, é motivada essencialmente pela respectiva forma de ingresso. Apesar das naturais e humanas deficiências, o sistema democrático constitui, sem sombra de dúvida, o processo mais cos. No entan candidatos a cargos públifugia a essa evidêncitério habitual de escolha de servidores paternalista. Por isso era o filhotismo político, o protecionismo cêrca de dez por isso, em previsão certamente otimista, apenas crivo seletivo do cento dos atuais funcionários se submeteram ao de 600.000 - ingresurso. Todos os demais - e totalizam mais por vias tran - ingressaram no serviço público por meios espúrios, formalmentensversas. Embora a exigência de concurso já fôsse procuraram recursos nem Administração e o Legislativo sempre teias de aranharsos nem sempre plausiveis para escapar das funcões de contra exigência legal: os cargos ditos isolados, as credenciados, avutado e de tarefeiros, os denominados eventuais, dêem. Assim, avulsos ou quaisquer outros apelidos que se lhes permanentes à margem das previsões fixadas nos quadros modalidades do funcionalismo, proliferavam as mais variadas requisitos de pessoal, cujo ingresso se fazia sem os mínimos

Posteriormente, inúmeras disposições constitucionais ou legais vieram beneficiar os que ocupavam interinamente cargos públicos e os que prestavam serviços sob qualquer das mencionadas formas, destacando-se o parágrafo único do artigo 18 e o artigo 23 do Ato das Disposições Constitucionais Transitórias de 18 de setembro de 1946, o artigo 261 do Estatuto dos Funcionários, as Leis $\mathrm{n}^{\mathrm{9s}} 2.284$, de 1954, 3.483, de 1958, 3.966, de 1961, 3.967, de $1961,4.054$, de 1962 , 4.069, de 1962 (parágrafo único do
artigo 23) e 4.242 , de 1963 (artigo 50). Assim, todo êsse 
pessoal estabilizado passou a integrar a categoria de funcionário, com os direitos e vantagens dos antigos titulares, entre os quais os que ingressaram no serviço mediante prévia habilitação em concurso.

Com o advento da Lei $n^{\circ} 4.345$, de 26 de junho de 1964 , (artigo 23) e, posteriormente, da Lei n? 5.117, de 29 de setembro de 1966, foi determinada, expressa e inequivocamente, a exigência de concurso para ingresso no serviço público, inclusive para servidores ou empregados submetidos ao regime da legislação trabalhista, a exemplo do denominado "pessoal temporário», previsto no Capitulo IV da Lei $\mathrm{n}^{\circ} 3.780$, de 12 de julho de 1960. Esse princípio, aliás, está consagrado na Constituição de 24 de janeiro de 1967 ( $« A$ nomeação para cargo público exige aprovação prévia em concurso público de provas ou de provas e títulos» - artigo $95, \S 1^{\circ}$ ). A confirmação dessa norma democrática, conjugada com a supressão do nocivo instituto da interinidade, vieram tranqüilizar a primeira investidura no serviço.

Mesmo assim, ainda se vem encontrando recursos e subterfúgios para tergiversar o requisito taxativo, através de pessoas admitidas sem qualquer ato formalizado e retribuidas mediante recibo, com o respectivo pagamento efetuado por dotações orçamentárias estranhas à especificamente destinada a «pessoal». Essa prestação de serviços deveria ser eventual e transitória, mas a Administração vem utilizando o permissivo legal para o ingresso de pessoal técnico, administrativo e auxiliar para a execução de atividades caracteristicamente permanentes. Dêsse modo, não há como fugir ao óbvio: o conjunto de pessoas pagas mediante simples recibo já constitui, em inúmeros órgãos, verdadeiro Quadro de Pessoal, rivalizando e não raro suplantando o corpo permanente de funcionários.

Diante dessa situação de fato, impõe-se a adoção de providências imediatas e enérgicas, a fim de possibilitar ao funcionalismo desqualificado a aquisição dos conhecimentos indispensáveis ao satisfatório desempenho das atribuições próprias dos cargos de que são ocupantes. $\mathrm{O}$ único meio racional para conseguir-se semelhante objetivo seria o treinamento intensivo, através de cursos tècnicamente planejados, nos quais se ministrassem conhecimentos teórico-práticos, entremeados com a aprendizagem das técnicas de trabalho normalmente utilizáveis na execução das tarefas típicas dos cargos. Incentivar-se-iam, dêsse modo, os funcionários a habilitarem-se ao exercício profissional, certos de que a incapacidade de assimilação dos conhecimentos ministrados nos cursos e a reação negativa ao treinamento seriam fatôres que influiriam, decisivamente, na permanência no serviço, tendo em vista que a comprovada ineficiência funcional caracteriza causa legal de demissão (artigo 100 do Decreto-lei n²00, de 1967).

Por outro lado, o problema salarial constitui poderoso e preponderante fator de integração do funcionário público em sua 
carreira profissional, contribuindo para a permanência do pessoal qualificado, que se vê solicitado, a cada instante, por outros empregadores, com polpudas ofertas pecuniárias. Na realidade, não se pode admitir a exata idéia de profissionalização sem que - Estado-empregador retribua, condignamente, quem lhe presta serviços. Pela sua relevância, o problema vem sendo debatido em tôdas as áreas ideológicas, inclusive pelos doutrinadores da teoria cristã do trabalho, notadamente através das encíclicas papais de caráter social (LEÃO XIII - «Rerum Novarum»;
PIO XI - Quadragésimo Ano»; Joño XXIII - «Mater et
Magistra»).

No Serviço Público Brasileiro, o problema não tem sido
satisfatòriamente circunstâncias. equacionado, por uma série infindável de Administração Eão principio, na fixação dos vencimentos, a funcionários a não considera a situação sócio-familiar de seus sociólogos católicos come do salário social, preconizado pelos humano. É de jos como a forma ideal de retribuição do trabalho se descurou, de justiça declarar -se, todavia, que o Estado não amenizar a rigidez de setlo, dêsse aspecto, visto como procura do salário familia de seu sistema salarial com a institucionalização quantitativo total - complemento da retribuição normal, cujo que possua o funcionário acôrdo com o número de dependentes Eossua o funcionário.

do serviço executado amplo, o salário se traduz na contrapreśtação diversos fatôres, tado. E na sua fixação devem ser considerados dido na realizas, tais como o esfôrço físico ou intelectual despenà finalidade ḑãa da tarefa, a relevância da atividade em relação característico da emprêsa ou da entidade e o grau de dificuldade Observado trabalho executado.

orientar rervados tais característicos, o princípio nuclear que deve tratamento uma salutar política salarial é o da uniformidade de natureza ou de iguale àqueles que executam trabalho de idêntica e inexpugnável igual graduação de complexidade. É tradicional consagrado universalmente de "salário igual para igual trabalho», inobservância dessa norma fundamental, de caráter mesmo axiomático, acarreta profundas injustiças, com sérias implicações no moral da equipe incumbida de realizar as atividades fins e meios da organização. No Serviço Público Brasileiro, em particular, o descumprimento dêsse princípio vem provocando descontentamento generalizado do funcionalismo e ocasionando encadeadas reivindicações: administrativas, legislativas e judiciárias.

Com o decurso do tempo, ao invés de solucionar tão cruciante problema social, que afeta o sistema de vida e o bem-ëstar familiar de vários milhões de pessoas, a tendencia vem sendo de agravá-lo cada vez mais, sob a maléfica influência da espiral ascendente do custo de vida, deglutidora insaciável dos frutos do trabalho de quem percebe salário fixo, apesar dos meritórios 
esforços do Govêrno no sentido de abater ou pelo menos domesticar o monstro da inflação.

Urge, portanto, uma criteriosa reformulação da política salarial no tocante ao funcionalismo federal, inclusive com o propósito de abandonar o nocivo e discriminatório apêlo a recursos esdrúxulos e condenáveis de aumentos camuflados de vencimentos: a aplicação quase indiscriminada do regime excepcional do tempo integral e dedicação exclusiva, a extensão da gratificação pela representação de gabinete, além de sua destinação específica, o pagamento extraordinário, mediante recibo, a pretexto de execução de trabalhos técnicos ou especializados etc.

No entanto, o problema salarial do funcionalismo sòmente poderá ser integralmente solucionado com a revisão do atual Plano de Classificação, implantado pela Lei $\mathrm{n}^{\circ} 3.780$, de 12 de julho de 1960, que objetivou a uma planificação racional dos cargos e funções então existentes no Serviço Público Civil do Poder Executivo, com o elevado propósito de corrigir as anomalias decorrentes da assistematização reinante.

É certo que, do ponto-de-vista estritamente técnico, o Plano de Classificação de Cargos constitui instrumento de trabalho dissociado de qualquer Plano de Pagamento ou de Remuneração. Essa dissociação, porém, não é completa nem absoluta. Isso porque a Classificação de Cargos terá de ser planejada, atentando-se para múltiplos fatôres, inclusive o sistema de retribuição vigente ou a vigorar no futuro, havendo, quase sempre, necessidade de recíprocas adaptação e coordenação.

No caso brasileiro, as modificações introduzidas na proposta executiva de sistematização dos cargos públicos, durante a sua tramitação legislativa, complementadas com as porventura bcm intencionadas correções ou distorsões parciais, desfiguraram por completo o planejamento originário, tornando-se imperiosa e inadiável a sua reformulação, simultâneamente com as demais medidas preconizadas no presente artigo, a fim de possibilitar à Administração Pública Federal contar com equipes homogêneas de funcionários, capazes de executar, com pleno êxito, a reforma administrativa já em fase inicial de implantação.

Impõem-se, para isso, pormenorizados levantamento e exame de tôdas as atividades exercitadas pela Administração, a fim de agrupá-las adequadamente nos diversos Ministérios ou entidades de administração indireta, evitando os malefícios da organização atual. Paralelamente, proceder-se-ia à minuciosa análise do trabalho executado, à base da estrutura recomendada, com a finalidade de conhecer-se, com exatidão, o pessoal imprescindivel ao desempenho das atribuições de cada nôvo órgão. Essas providências, efetuadas simultânea e coordenadamente, permitiriam a implantação - 1) de uma organização consentânea com a dinâmica administrativa brasileira, e 2) de radical reformulação do problema de pessoal no Serviço Público. 